06

\title{
Влияние водородной атмосферы на свойства пленки оксида алюминия на титане ВT1-0
}

\author{
(C) В.С Сыпченко, Ван Цайлунь, Н.Н. Никитенков, Ю.И. Тюрин, Т.И. Сигоруссон, Е.С. Киселева \\ Национальный исследовательский Томский политехнический университет, \\ 634034 Томск, Россия \\ e-mail: Kellymod53@mail.ru
}

(Поступило в Редакцию 22 января 2018 г.)

Работа посвящена взаимодействию пленки оксида алюминия, нанесенной на технически чистый титан марки ВТ1-0 методом магнетронного реактивного напыления, с водородсодержащей атмосферой. Время выдержки данной системы в водородсодержащей атмосфере составляло $1-4 \mathrm{~h}$ при прочих неизменных параметрах. Получены данные по распределению водорода по глубине (толщине пленки) и его содержанию в тонкопленочной системе, выявлено влияние времени выдержки в водородной атмосфере на адгезию коэффициент трения пленки, определена поверхностная электропроводность и распределение водорода в пленке оксида алюминия.

DOI: $10.21883 / J T F .2019 .04 .47312 .36-18$

\section{Введение}

Новые технологии в области металлургии не могут обеспечить полную защиту от проникновения водорода вглубь материала. Поэтому для целей защиты конструкционных и функциональных материалов от водородного охрупчивания остается актуальной разработка технологий создания тонкопленочных покрытий [1-8]. Свойства пленки оксида алюминия $\left(\mathrm{Al}_{2} \mathrm{O}_{3}\right)$ были исследованы на сталях и цирконии. Большинство проведенных исследований на пленках $\mathrm{Al}_{2} \mathrm{O}_{3}$ были выполнены в водородной среде при давлениях $<100 \mathrm{kPa}$ и установлено, что окисные пленки (слои) являются эффективным барьером от проникновения водорода [1-8].

В работах [1-5] измеряли проникновение водорода через пленку $\mathrm{Al}_{2} \mathrm{O}_{3}$ на аустенитной нержавеющей (AISI 316L) и мартенситной сталях (DIN 1.4914) и показали, что водородная проницаемость через пленку $\mathrm{Al}_{2} \mathrm{O}_{3}$, оказалась в $10^{2}-10^{3}$ раз меньше, чем у непокрытых образцов, и при толщинах покрытия $18-44 \mu \mathrm{m}$ толщина не влияет на проницаемость водорода и защитные свойства пленки $\mathrm{Al}_{2} \mathrm{O}_{3}$. В [6] изучали многослойные покрытия $\mathrm{Al}_{2} \mathrm{O}_{3}$, нанесенные вакуумно-плазменным распылением на мартенситную сталь (DIN 1.4914), которые показали высокую стойкость к проникновению дейтерия. G.T. Murray и др. [7] измерили предел прочности осажденных покрытий $\mathrm{A}_{2} \mathrm{O}_{3}, \mathrm{SiO}_{2}$ и $\mathrm{Si}_{3} \mathrm{~N}_{4}$ на мартенситную сталь с последующим наводороживанием $\left(P=13.8 \mathrm{MPa}, T=200^{\circ} \mathrm{C}\right.$ в течение $\left.24 \mathrm{~h}\right)$; в работе не указано содержание водорода в покрытиях образца, но авторы указывают, что влияние водорода на поверхность покрытия $\mathrm{A}_{2} \mathrm{O}_{3}$ не оказывает никакого воздействия и не приводит к деформации пленки. В работе J. Yamabe [8] представлены двуслойные $\left(\mathrm{A}_{2} \mathrm{O}_{3} / \mathrm{Fe}-\mathrm{Al}\right)$ и трехслойные $\left(\mathrm{Al}_{2} \mathrm{O}_{3} / \mathrm{Al}_{2} \mathrm{O}_{3} / \mathrm{FeAl}\right)$ покрытия (толщина слоя $\sim 300 \mathrm{~nm})$, нанесенные на цилиндрические трубки из аустенитной нержавеющей стали путем погружения в расплавленный сплав алюминия. Образцы с покрытием подвергались воздействию газообразного водорода при $10-100 \mathrm{MPa} \mathrm{при} 270^{\circ} \mathrm{C}$ в течение $200 \mathrm{~h}$. В результате оба покрытия показали высокую стойкость к водороду при $10 \mathrm{MPa}$. Тем не менее стойкость двуслойных покрытий явно уменьшается с увеличением давления в отличие от трехслойных, которые показали превосходные защитные свойства от водорода в широком диапазоне давлений 10-100 МРa.

Целью настоящей работы является изучение влияния водорода на тонкопленочную систему оксида алюминия на титане, а именно распределение водорода, адгезионные и сорбционные свойства пленки, изменение коэффициента трения.

\section{Экспериментальная часть}

В качестве объекта исследования выступали образцы титана марки ВТ1-0 с пленкой $\mathrm{Al}_{2} \mathrm{O}_{3} \quad\left(\mathrm{Al}_{2} \mathrm{O}_{3} / \mathrm{Ti}\right)$. Образцы титана размером $20 \times 20 \times 1 \mathrm{~mm}$ изготавливались методом электроискровой резки. Поверхность образцов до насыщения водородом механически шлифовали и полировали.

Нанесение пленки производилось методом магнетронного реактивного распыления. Технология нанесения покрытий была следующей: образцы из титана помещались на подвижный столик, и камера откачивалась до вакуума $P=4 \cdot 10^{-3} \mathrm{~Pa}$ с последующей ионной очисткой $(\mathrm{Ar})$ при следующих параметрах пучка: $U=2.5 \mathrm{kV}, I=0.2 \mathrm{~A}$. Когда мишень очищалась от ненужной оксидной пленки, в камеру добавлялся кислород, и магнетронная система переводилась в рабочий режим: $P=2 \cdot 10^{-1} \mathrm{~Pa}$, $U=0.8 \mathrm{kV}, I=10 \mathrm{~mA}$. После стабилизации параметров разряда производилось магнетронное напыление пленки оксида алюминия. Толщина покрытий $\sim 400 \mathrm{~nm}$. 
Выдерживание в водородной атмосфере титана ВТ1-0 и системы $\mathrm{Al}_{2} \mathrm{O}_{3} / \mathrm{Ti}$ осуществлялось на установке „Gas Reaction Controller“ со следующими параметрами: давление водорода в камере $P=2 \cdot 10^{6} \mathrm{~Pa}(2 \mathrm{~atm})$, температура $T=400^{\circ} \mathrm{C}$ в течение $1,2,3$ и $4 \mathrm{~h}$.

Содержание водорода в исследуемых образцах определялось как во время выдерживания в водородной атмосфере по изменению давления в рабочей камере, так и на анализаторе водорода RHEN-602 и методом термостимулированного газовыделения (ТСГВ).

Распределение химических элементов в системе $\mathrm{Al}_{2} \mathrm{O}_{3} / \mathrm{Ti}$ исследовалось на спектрометре тлеющего разряда GD-PROFILER 2, адгезионная прочность покрытий исследовалась на Micro-Scratch Tester MST-S-AX0000. Режимы испытания на адгезионную прочность были следующие: нагрузка $F=20 \mathrm{~N}$, скорость нагрузки $v=19.99 \mathrm{~N} / \mathrm{min}$, длина царапины $L=10 \mathrm{~mm}$.

Коэффициент трения системы $\mathrm{Al}_{2} \mathrm{O}_{3} / \mathrm{Ti}$ определялся на высокотемпературном трибометре. Режимы испытания были следующие: радиус шарика $d=2.98 \mathrm{~mm}$, линейная скорость $3 \mathrm{~cm} / \mathrm{s}$, нормальная нагрузка $N=1 \mathrm{~N}$, температура $T=23^{\circ} \mathrm{C}$ (комнатная).

Измерения поверхностной электропроводимости осуществлялись методом „накладных электродов“ (изготовлены из меди). Величина напряжения менялась в диапазоне $0.01-0.09 \mathrm{~V}$, нижний предел выбран из возможности генератора, верхний предел - с целью того, чтобы не допустить пробоя пленки из-за высокой напряженности электрического поля. По полученным вольтамперным характеристикам (BAX) поверхностную электропроводность рассчитывали по формуле

$$
\sigma=\frac{I}{U} \frac{L}{d}
$$

где $\sigma$ - поверхностная электропроводность (в сименcax), $U$ - значение приложенного напряжения, $I-$ измеренная сила тока, $d-$ расстояние между электродами $(d=2 \mathrm{~mm}), L-$ размер электрода $(L=7 \mathrm{~mm})$.

\section{Результаты и их обсуждение}

В табл. 1 приведены значения массового содержания водорода в системе $\mathrm{Al}_{2} \mathrm{O}_{3} / \mathrm{Ti}$ в зависимости от времени выдержки в водородной атмосфере. С увеличение времени выдержки от 1 до $3 \mathrm{~h}$ содержание водорода в образцах возрастает незначительно (за исключением данных, полученных с „Gas Reaction Controller"), a после $4 \mathrm{~h}$ наблюдается резкое увеличение содержания водорода. Такое различие может быть связано с тем, что с увеличением времени выдержки в водородной атмосфере пленка модифицируется под действием водорода, и водород проникает через пленку. В работе [9] было показано, что после насыщения в водородной среде пленок оксида алюминия пленка растрескивается, но при этом ее защитные свойства по проникновению водорода сохраняются.

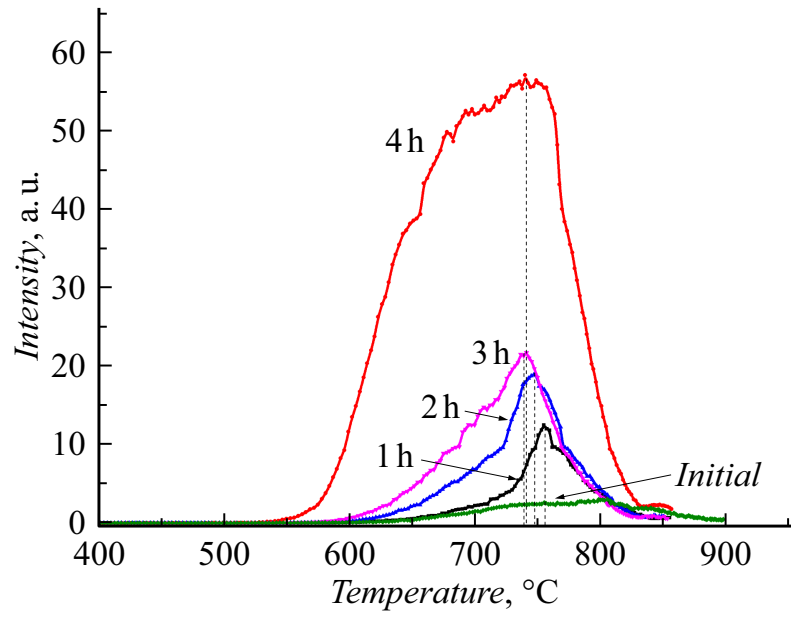

Рис. 1. Термодесорбционные спектры выхода водорода в зависимости от времени выдержки в водородной атмосфере $(1-4 h)$.

На рис. 1 представлены зависимости интенсивностей выделения $\mathrm{H}_{2}$ из системы $\mathrm{Al}_{2} \mathrm{O}_{3} / \mathrm{Ti}$, выдержанной в водородной атмосфере в течение 1, 2, 3 и 4 h. Скорость нагрева составляла $1^{\circ} \mathrm{C} / \mathrm{s}$. На основании спектров термостимулированного выхода водорода в программе OriginLab рассчитаны данные интегрального выхода газа (табл. 1).

Из зависимости на рис. 1 можно видеть, что при увеличении времени выдержки в водородной атмосфере возрастает концентрация водорода в системе $\mathrm{Al}_{2} \mathrm{O}_{3} / \mathrm{Ti}$. Стоит обратить внимание, что при увеличении времени выдержки наблюдается смещение температурного пика в область более низких температур (табл. 2). Такое смещение обусловлено разными (уменьшением) энергиями активации десорбции. Наличие двух температурных пиков на образцах после $4 \mathrm{~h}$ выдержки в водородной атмосфере связано с образование гидридов титана и их разложения при термическом нагреве.

На рис. 2 представлены результаты распределения химических элементов пленки и подложки по глубине, полученные на спектрометре тлеющего разряда GD-PROFILER2. Видно, что в исходной пленке (рис. 2,a) содержится водород, что не противоречит данным, представленным в табл. 1. Наличие водорода в пленке связано с его проникновением в процессе нанесения и формирования пленки. Сравнивая содержания $\mathrm{H}_{2}$ на рис. 2, $a-e$, можно видеть, что по мере увеличения времени выдержки (от 1 до 4 h) в водородной атмосфере концентрация водорода возрастает. Низкое содержание кислорода в пленке связано с низкой чувствительностью пробора по кислороду и азоту.

На рис. 3 представлены результаты трибологических испытаний для покрытий $\mathrm{Al}_{2} \mathrm{O}_{3}$ на подложке титана. Из представленной зависимости видно, что наименьшим коэффициентом трения $(\sim 0.1)$ обладают образцы после $1 \mathrm{~h}$ выдержки в водородной атмосфере, и с 
Таблица 1. Массовое содержание водорода в системе $\mathrm{Al}_{2} \mathrm{O}_{3} / \mathrm{Ti}$

\begin{tabular}{|c|c|c|c|c|c|}
\hline Время выдержки в водородной атмосфере, $\mathrm{h}$ & Исходный & 1 & 2 & 3 & 4 \\
\hline Содержание водорода, wt.\% & & 0.032 & 0.113 & 0.610 & 0.750 \\
\hline Массовое содержание водорода по анализатору водорода RHEN-602, ppm & 85.5 & 140.3 & 212.8 & 344.3 & 1030.8 \\
\hline Интегральный выход водорода по данным ТСГВ, a.u. & 468 & 821 & 1524 & 2007 & 8807 \\
\hline
\end{tabular}

Таблица 2. Энергия активации десорбции

\begin{tabular}{l|c|c|c|c|c|c}
\hline Время выдержки в водородной атмосфере, $h$ & Исходный & 1 & 2 & \multicolumn{2}{|c}{4} & \multicolumn{2}{|c}{4} \\
\hline Температурный пик С & 805 & 757 & 748 & 743 & 695 & 743 \\
Энергиями активации десорбции, $\mathrm{eV}$ & 4.58 & 4.38 & 4.34 & 4.31 & 4.12 & 4.32
\end{tabular}

Таблица 3. Адгезионной прочности пленки оксида алюминии на титане

\begin{tabular}{c|c|c|c|c|c}
\hline Время выдержки в водородной атмосфере, $\mathrm{h}$ & 0 & 1 & 2 & 3 & 4 \\
\hline Адгезионная прочность, $\mathrm{N}$ & $1.2 \pm 0.3$ & $4.9 \pm 0.1$ & $5.5 \pm 0.4$ & $7.8 \pm 0.7$ & $3.1 \pm 0.7$
\end{tabular}

Таблица 4. Значения тока и напряжения с пленки $\mathrm{Al}_{2} \mathrm{O}_{3}$

\begin{tabular}{l|l|l|l|l|l|l|l|l|l}
\hline Напряжение, V & 0.01 & 0.02 & 0.03 & 0.04 & 0.05 & 0.06 & 0.07 & 0.08 & 0.09 \\
\hline Ток $\left(\right.$ исходный, $\mathrm{A} \cdot 10^{-8}$ & 1.3 & 2.23 & 3.14 & 4.05 & 4.9 & 5.85 & 6.74 & 7.66 & 8.56 \\
\hline Ток $(1 \mathrm{~h}), \mathrm{A} \cdot 10^{-8}$ & 1.37 & 2.28 & 3.18 & 4.09 & 4.99 & 5.89 & 6.77 & 7.62 & 8.59 \\
\hline Ток $(2 \mathrm{~h}), \mathrm{A} \cdot 10^{-8}$ & 1.47 & 2.37 & 3.26 & 4.16 & 5.06 & 5.96 & 6.85 & 7.46 & 8.66 \\
\hline Ток $(3 \mathrm{~h}), \mathrm{A} \cdot 10^{-8}$ & 1.53 & 2.43 & 3.32 & 4.23 & 5.12 & 6.02 & 6.9 & 7.8 & 8.7 \\
\hline Ток $(4 \mathrm{~h}), \mathrm{A} \cdot 10^{-8}$ & 1.6 & 2.5 & 3.4 & 4.3 & 5.2 & 6.1 & 7 & 7.9 & 8.8
\end{tabular}

увеличением времени выдержки он возрастает вплоть до 3 h. После 3 и 4 h выдержки в водородной среде наблюдаются равные коэффициенты трения $(\sim 0.16)$, что свидетельствует о накоплении водорода в пленке.

Изменение свойств пленки связано с диффузией атомарного водорода через нее. Свободные атомы водорода адсорбируются на поверхности пленки и диффундируют в ее приповерхностные слои, это приводит к модификации покрытия. На этом этапе наблюдается усиление водородного диспергирования, причем на поверхностности не наблюдаются видимые повреждения. При увеличении времени выдержки водород через эти модифицированные слои легко проникает к участкам поверхности подложки, при этом скорость его диффузии возрастает. На этом этапе наступает стадия разрушения пленки мгновенное разрушение поверхностного слоя пленки. Водород проникает вглубь пленки, в микропустоты, где он соединяется в молекулы. Пустоты „закрываются“, и это приводит к повышению давления молекулярного водорода на стенки микротрещин, происходит мгновенное разрушение пленки, по всем ранее возникшим микротрещинам, и увеличение коэффициента трения.
В табл. 3 представлена адгезионная прочность пленки оксида алюминия на титане ВТ1-0. Из представленных данных следует, что после $4 \mathrm{~h}$ выдержки в водородной атмосфере пленка начинает отслаиваться (падает адгезионная прочность), это может быть связано с накоплением водорода на границе раздела пленка-подложка и, возможно, образованием гидридов в титане [9]. В случае исходной пленки и после выдержки в течение $1-3 \mathrm{~h}$ сила сцепления пленки с подложкой возрастает, очевидно, за счет образования водородных связей пленка-подложка.

В табл. 4 представлены данные тока и напряжения, на основании которых рассчитывалась поверхностная электропроводимость пленки $\mathrm{Al}_{2} \mathrm{O}_{3}$ на титане ВТ1-0 по формуле (1) после разных времен выдержки в водородной атмосфере. Полученные зависимости представлены на рис. $3, b$; из них видно, что в зависимости от времени выдержки в водородной атмосфере поверхностная электропроводимость пленки растет. Стоит отметить, что данный метод дает качественную зависимость, так как при расчете не учитываются геометрические размеры пластинок и краевые эффекты, возникающие на пластинках -электродах. 

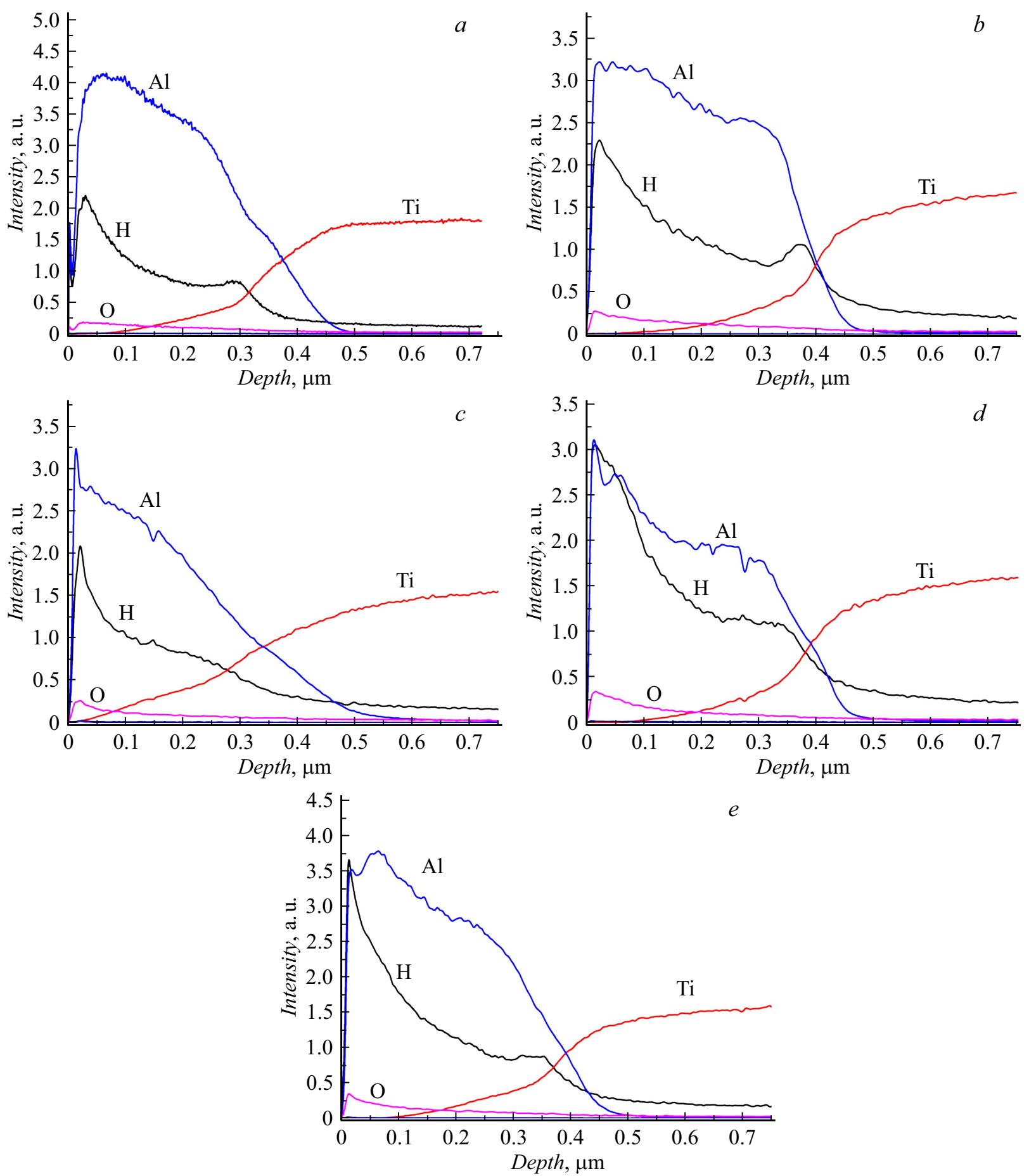

Рис. 2. Распределение химических элементов в системе $\mathrm{Al}_{2} \mathrm{O}_{3} / \mathrm{Ti}$ в исходном состоянии $(a)$ и в зависимости от времени выдержки в водородной атмосфере: $1(b), 2(c), 3(d), 4 \mathrm{~h}(e)$.

Из рис. $3, b$ можно видеть, что адсорбция атомов водорода на поверхности пленки $\mathrm{Al}_{2} \mathrm{O}_{3}$ сопровождается увеличением ее электропроводности, и с увеличением времени выдержки поверхностная электропроводимость пленки $\mathrm{Al}_{2} \mathrm{O}_{3}$ растет. Такое изменение электропроводимости пленки $\mathrm{Al}_{2} \mathrm{O}_{3}$ может быть объяснено на основе зонной структуры. Тонкие оксидные пленки могут обладать сплошной односторонней проводимостью, в случае же если пленка толстая $(0.5 \mu \mathrm{m}$ и более), то говорить об однородной проводимости нельзя. Так, объемные и пористые оксидные пленки за счет тонкого сплошного оксидного слоя, который всегда имеется на дне пор, очень слабо проявляют вентильные свойства.

$\mathrm{Al}_{2} \mathrm{O}_{3+m}$ является дырочным полупроводником $p$-типа, a с недостающим электроном $\mathrm{Al}_{2+n} \mathrm{O}_{3}-n$-типа. Таким образом, в процессе образования пленки оксида алю- 

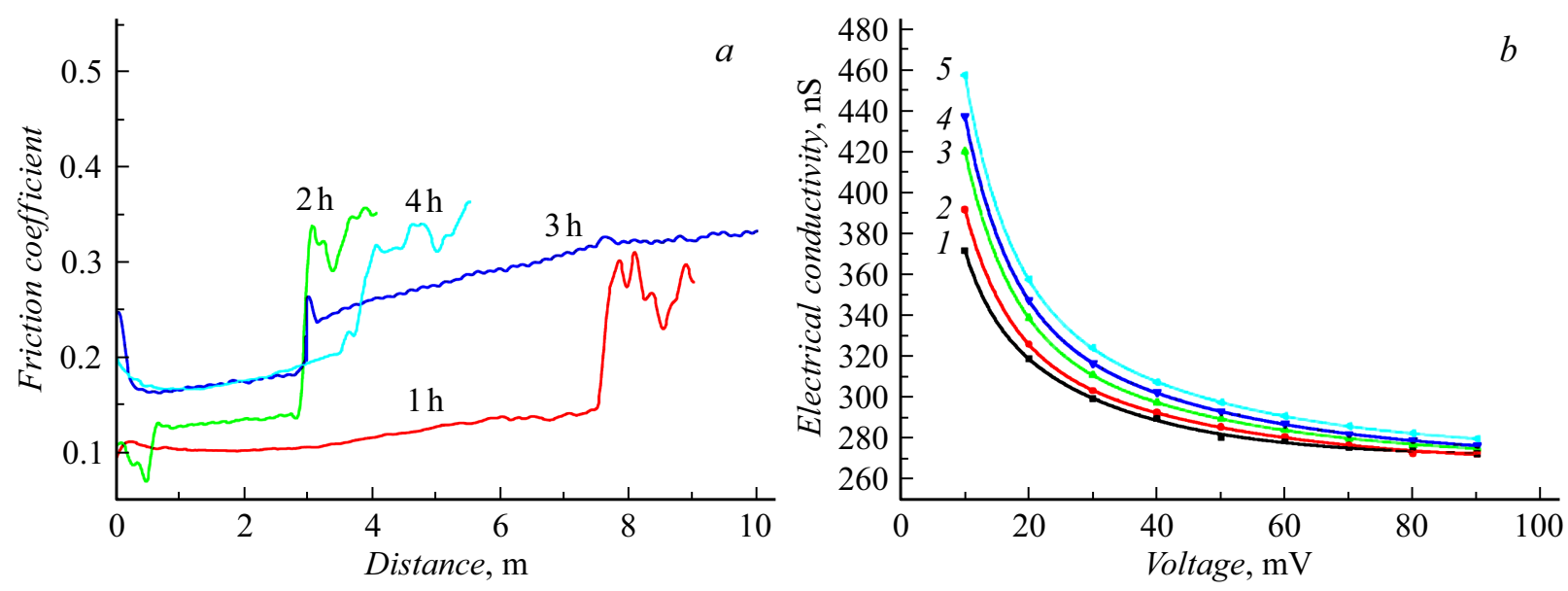

Pис. 3. $a-$ зависимость коэффициента трения пленки оксида алюминия на титане от времени выдержки в водородной атмосфере; $b$ - график зависимости поверхностной электропроводимости пленки $\mathrm{Al}_{2} \mathrm{O}_{3}$ на титане после разных времен насыщения водородом: 1 - исходный, $2-1,3-2,4-3,5-4 \mathrm{~h}$.

миния создается переход $p-n$-типа с промежуточным слоем диэлектрика. Известно, что при длительном пропускании электрического тока через оксидную пленку ионы перераспределяются, что приводит к частичному разрушению $p-n$-перехода. Пленка $\mathrm{Al}_{2} \mathrm{O}_{3+m}$ превращается в электронный полупроводник, который содержит избыток или дефицит ионов алюминия, что также зависит от условий. Аналогичное разрушение $p-n$-перехода наблюдается при нагревании оксидной пленки, в этом случае наблюдается обратная зависимость, т.е. концентрация ионов кислорода уменьшается, что приводит к увеличению избыточного количества ионов алюминия. В случае же взаимодействия водорода с оксидной пленкой, связывающего кислород, - приводит к превращению окиси алюминия в электронный полупроводник.

Часто при нанесении пленок образуются дефектные места, которые обладают высокой проводимостью. Причиной появления дефектов может служить неоднородная поверхность оксида (поры), что также влияет на электропроводимость в пленках.

\section{Заключение}

Проведенный комплекс исследований позволяет выделить следующие основные результаты:

1. Пленка на основе оксида алюминия препятствует проникновению водорода в титан с увеличением времени выдержки системы $\mathrm{Al}_{2} \mathrm{O}_{3} / \mathrm{Ti}$ в водородной атмосфере от 1 до $3 \mathrm{~h}$, а после $4 \mathrm{~h}$ наблюдается резкое увеличение содержания водорода, что свидетельствует о модификации пленки.

2. С увеличение времени выдержки в водородной атмосфере коэффициент трения пленки $\mathrm{Al}_{2} \mathrm{O}_{3}$ возрастает.

3. С увеличением времени выдержки в водородной атмосфере от 1 до $3 \mathrm{~h}$ адгезионные свойства пленки возрастают, а после $4 \mathrm{~h}$ падают, что связано с увеличением количества водорода на границе раздела пленка-подложка.

4. С увеличение времени выдержки в водородной атмосфере поверхностная электропроводность пленки повышается; это различие объясняется тем, что при пропускании тока через оксидную пленку ионы в пленке перераспределяются, и частично разрушается $p-n$ переход.

\section{Список литературы}

[1] Roberts R.M., Elleman T.S., Ralmour I.H., Verghese K. // J. Am. Ceram. Soc. 1979. Vol. 62. P. 495-499.

[2] Forcey K.S., Ross D.K., Wu C.H. // J. Nucl. Mater. 1991. Vol. 182. P. 36-51.

[3] Perujo A., Forcey K.S., Sample T. // J. Nucl. Mater. 1993. Vol. 207. P. 86-91.

[4] Song R.H., Pyun S. // J. Electrochem. Soc. 1990. Vol. 137. P. 1051-1056.

[5] Song R.G. // Surf. Coat. Technol. 2003. Vol. 168. P. 191-194.

[6] Perujo A., Serra E., Kolbe H., Sample T. // J. Nucl. Mater. 1996. Vol. 233-237. P. 1102-1106.

[7] Murray G.T., Bouffard J.P., Briggs D. // Metall. Trans. A. 1987. Vol. 18. P. 162-164.

[8] Yamabe J., Matsumoto T., Matsuoka S., Murakami Ya. // Int. J. Fract. 2012. Vol. 177. P. 141-162.

[9] Nikitenkov N.N., Vilkhivskaya O.V., Nikitenkov A.N., Tyurin Yu.I., Sypchenko V.S., Shulepov I.A. // Thin Solid Films. 2015. Vol. 591. P. 169-173. 